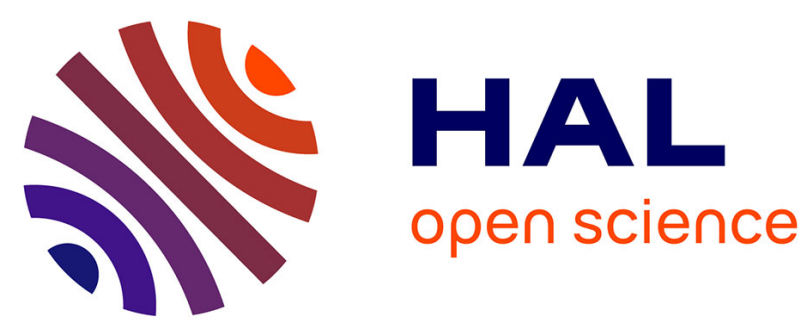

\title{
Room and low temperature electrical measurements for the interface characterization of titanium disilicides on silicon from multilayer titanium/silicon structures
}

P. Revva, A. Nassiopoulos, A. Travlos

\section{- To cite this version:}

P. Revva, A. Nassiopoulos, A. Travlos. Room and low temperature electrical measurements for the interface characterization of titanium disilicides on silicon from multilayer titanium/silicon structures. Journal de Physique IV Proceedings, 1994, 04 (C6), pp.C6-93-C6-98. 10.1051/jp4:1994615 . jpa00253109

\author{
HAL Id: jpa-00253109 \\ https://hal.science/jpa-00253109
}

Submitted on 1 Jan 1994

HAL is a multi-disciplinary open access archive for the deposit and dissemination of scientific research documents, whether they are published or not. The documents may come from teaching and research institutions in France or abroad, or from public or private research centers.
L'archive ouverte pluridisciplinaire HAL, est destinée au dépôt et à la diffusion de documents scientifiques de niveau recherche, publiés ou non, émanant des établissements d'enseignement et de recherche français ou étrangers, des laboratoires publics ou privés. 


\title{
Room and low temperature electrical measurements for the interface characterization of titanium disilicides on silicon from multilayer titanium/silicon structures
}

\author{
P. Revva, A.G. Nassiopoulos and A. Travlos* \\ Institute of Microelectronics, NCSR "Demokritos", P.O. Box 60228, I5310 Aghia Paraskevi Attikis, \\ Athens, Greece \\ * Institute of Materials Science, NCSR "Demokritos", P.O. Box 60228, 15310 Aghia Paraskevi Attikis, \\ Athens, Greece
}

\begin{abstract}
The interface of titanium disilicides $\mathrm{TiSi}_{2}$ on silicon formed by electron gun evaporation of silicon/titanium multilayers and subsequent annealing is characterised using current-voltage measurements on specially prepared Schottky diodes in the whole temperature range from room temperature down to $77 \mathrm{~K}$. In particular, the influence of the bilayer $\mathrm{Si} / \mathrm{Ti}$ thickness ratio, ranging between 2 and 3, on the barrier height of the diodes is studied and compared with the case of a diode formed by deposition of a single titanium layer and further annealing. The activation energies derived from the low temperature measurements have shown that the interface of the sample prepared with single layer deposition is more rough than the case of the sample prepared with deposition of multilayers using a bilayer thickness ratio $\mathrm{Si} / \mathrm{T} \mathrm{i}=2.5$ which is close to the calculated value for the stoichiometric films.
\end{abstract}

\section{INTRODUCTION.}

Titanium disilicides are used as contact layers on source and drain regions in micron and submicron complementary metal-oxide-semiconductor (C-MOS) circuits [1,2]. In sub-0.5 $\mu \mathrm{m}$ dimensions where the junction depth is very small (below $0.1 \mu \mathrm{m}$ ), the consumption of silicon required for the silicidation reaction from the substrate results in modification of the doping profile of the junction region. A solution to this problem is given by the deposition of both silicon and titanium either by co-deposition or by alternate $\mathrm{Ti}-\mathrm{Si}$ deposition and subsequent annealing so as silicidation takes place within the deposited material and the junction is not seriously altered.

In this work alternate titanium-silicon deposition by electron gun evaporation in high vacuum and annealing in nitrogen ambient are used for silicide formation. The properties of the film depend on the ratio of the thickness of the deposited silicon and titanium layers, $\mathrm{Si} / \mathrm{Ti}$, and the same applies to the interface of the $\mathrm{TiSi}_{2}$ with the silicon substrate. The film properties have been characterised in previous work [3-5]. In this paper the influence of the $\mathrm{Si} / \mathrm{Ti}$ thickness ratio on the $\mathrm{TiSi}_{2} / \mathrm{Si}$ interface has been studied using current-voltage characteristics performed at room and lower temperatures down to $77 \mathrm{~K}$ on specially prepared Schottky diodes. The bilayer Si-Ti thickness was ranging between $30 \mathrm{~nm}$ and $40 \mathrm{~nm}$. The titanium layer thickness was equal to $10 \mathrm{~nm}$ and the silicon thickness was varying between $20 \mathrm{~nm}$ and 
30nm, giving a Si/Ti thickness ratio between 2 and 3. A total of four Ti and five Si layers was used in every case. The obtained silicide was equal to $100 \mathrm{~nm}$. A silicide formed by deposition of a single titanium layer and further annealing was also prepared and used for comparison with the multilayer cases. A titanium on silicon diode was also measured at room temperature in order to verify that our results are in agreement with the literature.

\section{EXPERIMENTAL RESULTS AND DISCUSSION}

The Schottky diodes were made on both p-type and n-type silicon $\langle 100\rangle$ wafers with a resistivity of $1-3 \Omega \mathrm{cm}$ and a dry silicon oxide thermally grown on them. Optical lithography and wet etching were used in order to define a pattern of squares on $\mathrm{SiO}_{2}$ of side dimensions within the $0.7-1 \mathrm{~mm}$ range. Silicide formation on patterned areas was performed by alternate $\mathrm{Si}$-Ti deposition and annealing at $850^{\circ} \mathrm{C}$ in $\mathrm{N}_{2}$ ambient using the lift-off technique. A back ohmic contact was formed by aluminum deposition and annealing at $450^{\circ} \mathrm{C}$ in $\mathrm{N}_{2}$ ambient. Two different samples were used with $\mathrm{Si} / \mathrm{Ti}$ bilayer thickness ratios equal to 2.5 and 3 .

Rutherford Backscattering (RBS) measurements on the above samples published previously[3], showed that the film from multilayers with $\mathrm{Si} / \mathrm{Ti}=2.5$ is stoichiometric $\left(\mathrm{TiSi}_{2}\right)$ and so is the film from a single deposited layer. The case $\mathrm{Si} / \mathrm{Ti}=3$ gives an excess of $\mathrm{Si}$ within the film ( $\mathrm{TiSi}_{2.3}$ ). X-ray Diffraction measurements showed that the metallic orthorombic C-54 phase of $\mathrm{TiSi}_{2}$ is the only silicide phase present in the spectra from all the above cases. The resistivity obtained by the films is about $20-$ $25 \mu \Omega \mathrm{cm}$.

Current-voltage measurements are performed in the temperature range $77-300 \mathrm{~K}$ and are compared with those of scanning and transmission electron microscopy [3-5].

\subsection{Room Temperature measurements}

In figs. 1 and 2 we have plotted the current density-voltage characteristics, $J(V)$, measured at room temperature for several values of the multilayer ratio used on the p-type and n-type samples. The ideality factors are derived from the slopes of these curves and the values of the barrier heights are derived from the intercept of these curves with the $\mathrm{y}$-axis at $\mathrm{V}=0$ [6], $\mathrm{J}_{0}$, and are given in tables I and II.

The above parameters have been also derived for the case of a diode formed by deposition of a single layer titanium prior to annealing and was used as a reference to the literature.

The values of the barrier heights change from $0.61 \mathrm{eV}$ for the $\mathrm{Ti} / \mathrm{p}$-type $\mathrm{Si}$ diode to $0.53 \mathrm{eV}$ for the case of the $\mathrm{TiSi}_{2} / \mathrm{p}$-type $\mathrm{Si}$ diode formed from a single deposited $\mathrm{Ti}$ layer. In the case of the diodes formed on n-type Si the values of the barrier height change from $0.53 \mathrm{eV}$ to $0.61 \mathrm{eV}$ respectively. The above values are consistent with the literature [7]. The value of the barrier height in the case of $\mathrm{Si} / \mathrm{Ti}=2.5$ is $0.56 \mathrm{eV}$ for the p-type sample and $0.65 \mathrm{eV}$ for the n-type sample. The ideality factor for both samples is similar with the previous cases and near to unity.

In the case of the $\mathrm{Si} / \mathrm{Ti}=3$ sample deposited on $\mathrm{p}$-type $\mathrm{Si}$ (table I), the ideality factor $\eta$ is very high $(\eta \simeq 2)$ deviating very much from unity in comparison with the other ideality factors. The value of the resistance which is in series with the $\mathrm{TiSi}_{2} / \mathrm{Si}$ diode, derived from the upper part of the currentvoltage curve (fig.1) in higher forward bias is equal to $1700 \Omega$, very large compared with the low resistivity substrate used. Both arguments suggest that there is an interfacial layer in this case which is also seen in cross sectional transmission electron microscopy pictures (XTEM) [4,5]. Hence, there was no reason for diodes preparation on n-type samples.

The value of the barrier height in the case of $\mathrm{Si} / \mathrm{Ti}=2.5$ is bigger than the case of the single deposited layer for both the p-type and n-type samples. Although this observation seems to suggest a better interface for the case of $\mathrm{Si} / \mathrm{Ti}=2.5$ ratio, the difference $(\sim 0.03 \mathrm{eV})$ is very small to provide any qualitative comparison between the two interfaces. Due to this reason a study of the $J(V)$ at lower temperatures down to $77 \mathrm{~K}$ was made. 


\subsection{Low Temperature measurements}

In fig. 3 we have plotted the J(V) characteristics in the case of the single deposited layer on p-type samples -the ideality factors as derived at each temperature are given nearby the respective figure. Similar measurements were made in the case of the $\mathrm{Si} / \mathrm{Ti}=2.5$ and the ratio $\mathrm{J}_{0} / \mathrm{T}^{2}$ was derived at each temperature for both samples.

In fig. 4 we have plotted $\ln \left(\mathrm{J}_{0} / \mathrm{T}^{2}\right)$ versus $1000 / \mathrm{T}$ for the single and the $\mathrm{Si} / \mathrm{Ti}=2.5$ cases. There are two possible activation plots in both cases. The upper linear parts which correspond to the high temperature should yield the value of the barrier height at the absolute zero $(T=0 K), \Phi_{b}(0)$, according to the thermionic emission model and assuming that the barrier height increases linearly with lowering the temperature. This is evident from the value of the activation energy derived for both cases (fig.4) while in lower temperatures these values become different. Thermionic emission combined with recombination currents result in such a behaviour of the current-voltage characteristics. Recombination currents become dominant at low temperature and low forward bias. This is ascertained by the increasing deviation of the ideality factor from unity with lowering the temperature -its value is close to two at nitrogen temperature which is the case of a highly efficient recombination centre. The solid curve corresponding to the $77 \mathrm{~K}$ current-voltage characteristic on fig. 4 represents a fit of the sum of two exponentials arising from the thermionic emission and recombination currents $[6,7]$.

From fig. 4 it is seen that the low temperature current is larger in the case of the single deposited sample than the case of $\mathrm{Si} / \mathrm{Ti}=2.5$. Indeed the measurements of more important recombination currents in the case of the single deposited layer is in agreement with a more anomalous interface observed by both cross sectional transmission measurements (XTEM) and scanning electron microscopy (SEM) [3-5].

\section{CONCLUSION}

A study of the interface of the $\mathrm{TiSi}_{2} / \mathrm{Si}$ with current-voltage measurements at room temperature and after comparison with previous measurements of XTEM and SEM has shown that in the case of $\mathrm{Si} / \mathrm{Ti}=3$ there is an interfacial layer present which is formed due to extra silicon escaping from the film towards the interface. The interface in the case of $\mathrm{Si} / \mathrm{Ti}=2.5$ has a value of the barrier height slightly bigger than the corresponding value of the interface of the single deposited case and appears to have less electrically active interfacial defects. It seems that the silicon consumption from the substrate creates a more rough interface than the case where the substrate surface is covered with amorphous silicon and the silicide is formed after intermixture of the $\mathrm{Ti}$ and $\mathrm{Si}$ layers deposited with a thickness ratio of $\mathrm{Si} / \mathrm{T} \mathrm{i}=2.5$ close to the calculated value for the stoichiometric films.

\section{REFERENCES}

[1] A. L. Butler and D. J. Foster, IEEE Trans. Electron Devices ED-32 (1985) 150.

[2] C. Y. Ting, S. S. Iyer, C. M. Osburn, G. J. Hu and A. M. Schweighart, Electrochem. Soc. proc. 82 (1982) 254.

[3] A. G. Nassiopoulos, D. Tambouris, A. Travlos, A. Traverse, P. Aloupogiannis, J. Appl. Phys. 72(10) (1992) 4660.

[4] A. G. Nassiopoulos, N. Frangis, A. Travlos and P. Revva, Inst. Phys. Conf. Ser. No 134(4) (1993) 199.

[5] A. G. Nassiopoulos, N. Frangis, S. Logothetidis, S. Georga, Ch. Krontiras, N. Xanthopoulos and D. Tambouris, Thin Solid Films, (to appear).

[6] E. H. Rhoderick and R. H. Williams, Metal-Semiconductor Contacts, 2nd edition (Clarendon, Oxford 1988)

[7] P. Revva, A. G. Nassiopoulos and A. Travlos, J. Appl. Phys., (to appear). 
TABLE I: Values of the room temperature Schottky barrier heights and the ideality factors derived from $\mathrm{I}(\mathrm{V})$ measurements made on $\mathrm{TiSi}_{2} / \mathrm{p}$-type Si diodes, for various values of the multilayer deposition ratio $\mathrm{Si} / \mathrm{Ti}$.

\begin{tabular}{|c|c|c|c|c|}
\hline & Ti/Si diode & single & Si/Ti=2.5 & Si/Ti=3 \\
\hline n-ideal.factor & 1.07 & 1.14 & 1.15 & 1.9 \\
\hline $\begin{array}{c}\text { barrier height } \\
\Phi_{\mathrm{b}, \mathrm{eV}}\end{array}$ & 0.61 & 0.53 & 0.56 & 0.57 \\
\hline
\end{tabular}

TABLE II: Values of the room temperature Schottky barrier heights and the ideality factors derived from $I(V)$ measurements made on $\mathrm{TiSi}_{2} / \mathbf{n}$-type Si diodes, for various values of the multilayer deposition ratio Si/Ti.

\begin{tabular}{|c|c|c|c|}
\hline & Ti/Si diode & single & Si/Ti=2.5 \\
\hline n-ideal.factor & 1.07 & 1.12 & 1.17 \\
\hline $\begin{array}{c}\text { bartier height } \\
\Phi_{\mathrm{b}, \mathrm{eV}}\end{array}$ & 0.53 & 0.61 & 0.65 \\
\hline
\end{tabular}




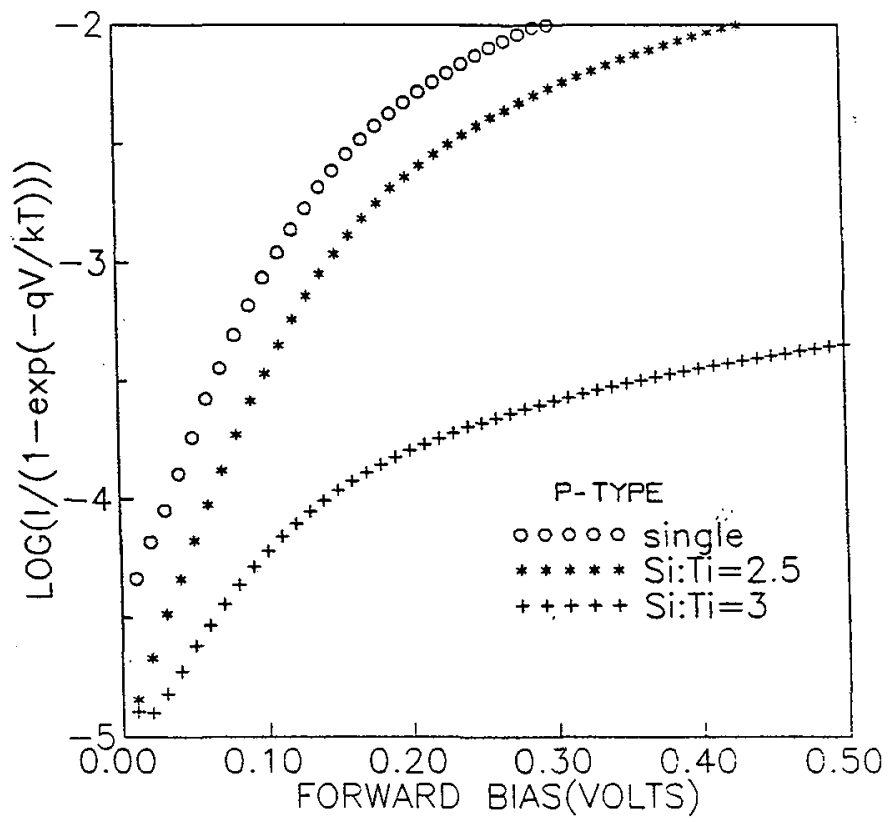

Fig. 1: Room temperature I(V) plots of $\mathrm{TiSi}_{2} / \mathrm{p}$-type $\mathrm{Si}$ diodes for several Si/Ti multilayer deposition ratios.

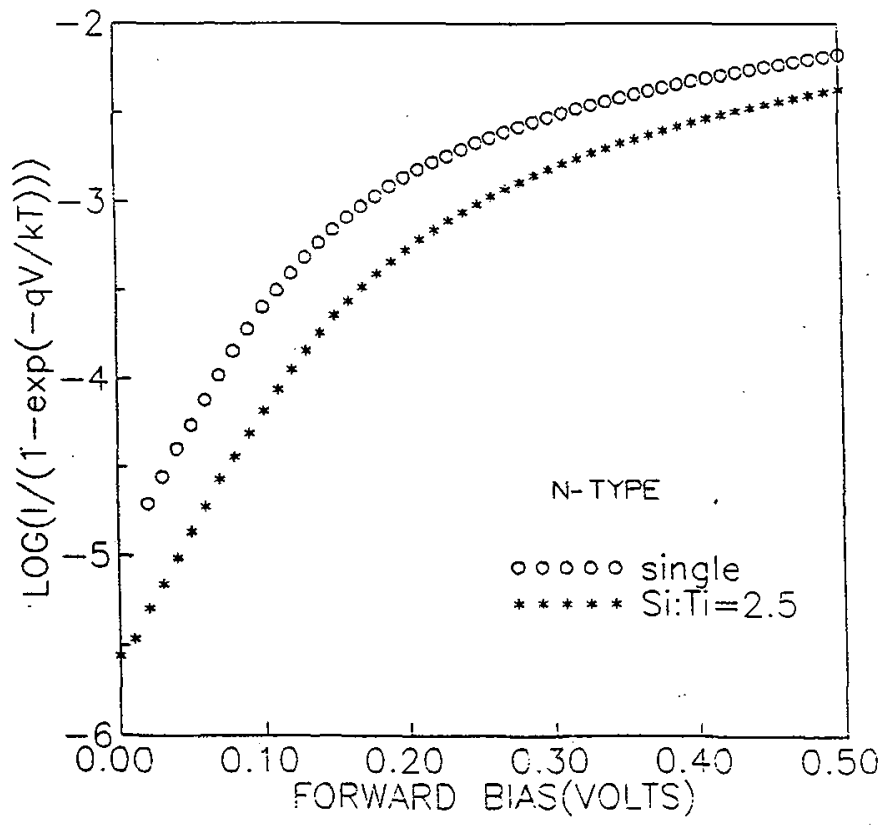

Fig. 2: Room temperature $\mathrm{I}(\mathrm{V})$ plots of $\mathrm{TiSi}_{2} / \mathrm{n}$-type $\mathrm{Si}$ diodes for several $\mathrm{Si} / \mathrm{Ti}$ multilayer deposition ratios. 


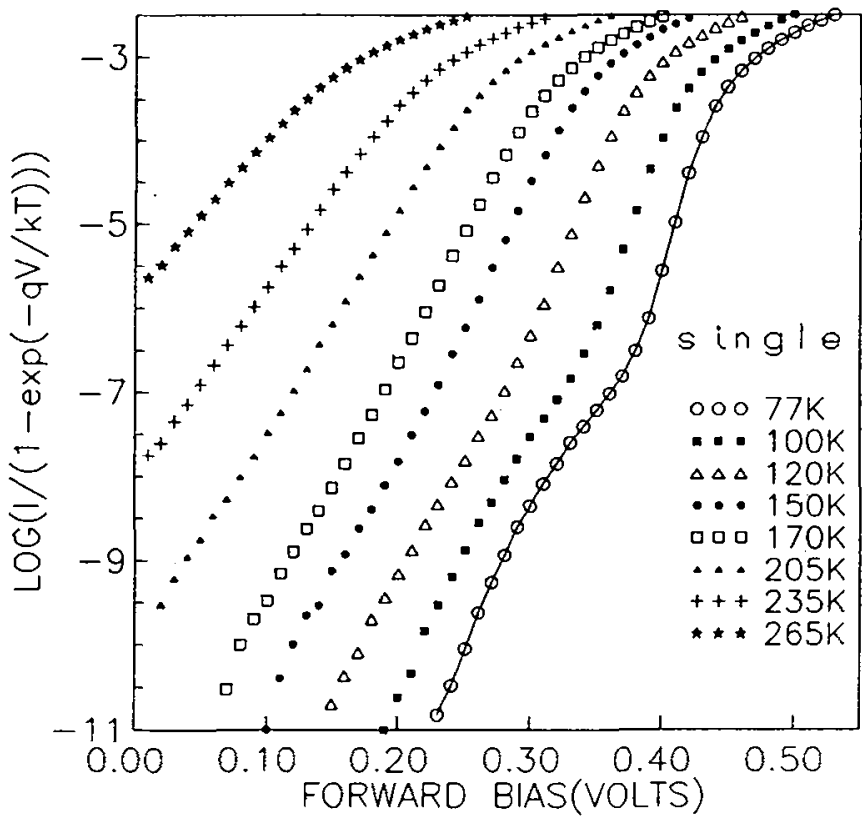

\begin{tabular}{|l|l|}
\hline$\eta$ & $T$ \\
\hline 21 & $77 \mathrm{~K}$ \\
\hline 1.8 & $100 \mathrm{~K}$ \\
\hline 1.5 & $120 \mathrm{~K}$ \\
\hline 13 & $150 \mathrm{~K}$ \\
\hline 1.05 & $170 \mathrm{~K}$ \\
\hline 1.1 & $205 \mathrm{~K}$ \\
\hline 106 & $235 \mathrm{~K}$ \\
\hline 1.13 & $265 \mathrm{~K}$ \\
\hline
\end{tabular}

Fig. 3: I(V) plots of $\mathrm{TiSi}_{2} / \mathrm{p}$-type Si diodes measured at several temperatures between $77 \mathrm{~K}$ and $300 \mathrm{~K}$, for the case of single deposited layer -the solid line is an example of the quality of the fit of two exponentials on the I(V) curve.

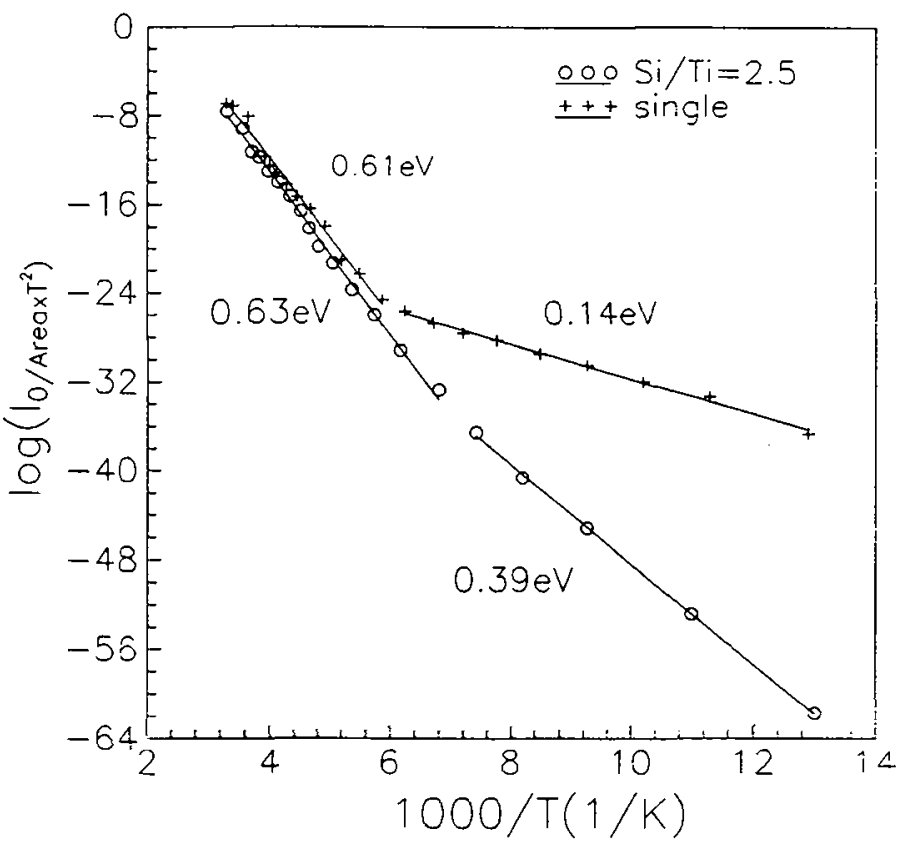

Fig. 4: Activation plots of the saturation current density $\mathrm{J}_{0}=\mathrm{I}_{0} /$ Area of $^{\mathrm{T} i S i} \mathrm{i}_{2} / \mathrm{p}$-type Si diodes for the case of single deposited and the case of $\mathrm{Si} / \mathrm{Ti}=2.5$. 